\title{
Penal Mediation to Dissolve Discord among Peasants in Guilan (Iran)
}

\author{
Seyedeh Fatemeh Seyed Saadat ${ }^{1} \&$ Saeed Hakimiha ${ }^{2}$ \\ ${ }^{1}$ Department of Law, Faculty of Humanities, Rasht Branch, Islamic Azad University, Rasht, Iran \\ ${ }^{2}$ Department of Law, Imam Hossein Comprehensive University, Tehran, Iran \\ Correspondence: Seyedeh Fatemeh Seyed Saadat, Department of Law, Faculty of Humanities, Rasht Branch, \\ Islamic Azad University, Rasht, Iran. E-mail: fatemehsyedssadat@gmail.com
}

Received: September 25, 2016 Accepted: October 28, 2016 Online Published: November 30, 2016

doi:10.5539/jpl.v9n10p187 URL: http://dx.doi.org/10.5539/jpl.v9n10p187

\begin{abstract}
Present research was accomplished to survey penal mediation role in dissolving discord among peasants in Guilan province of Iran. Restorative justice is to make all parties participate in discord dissolution process and to decriminalize it with tools like mediation. It is based on a principle in which no culprit is pursued and also it is planning to relief victim. The law of criminal procedure in Article 82, projects "mediation" subject in crime deterrent grades $6,7,8$. These crimes usually are pardonable or at least private complainer pardon is effective in mitigation. This issue causes reduction of criminal files and also criminal costs. It facilitates the social revive of the criminal. Modern criminal justice believes that penal mediation as one of settlement methods should follow special regulations which guarantee criminal and victim rights. This research is presented in four sections. This research is practical and the method is descriptive - analytical. Statistical population is consisting of 160 persons from many different villages in Guilan province. In order to collect data, questionnaire was administered and data analysis was performed using SPSS software. In forth section of this research, considering related questions, we were after to prove hypotheses. Results showed that criminal mediation can be settled by meetings performed by elders of villages in Guilan province and it prevents fights and claim .As a new look of criminal justice, it can be used as an appropriate instrument for judiciary.
\end{abstract}

Keywords: settlement, discord, mediation, restorative justice, criminal justice, Guilan

\section{Introduction}

Many restorative justice advocates believe that mediation is one of the oldest and most effective ways that has been used in different part of the world that differs from other methods in some aspects. In a sense, we can consider mediation as a touchstone of restorative justice. In mediation method, there is an atmosphere that both victim and victim can converse each other face to face without any pressure or imposing terms from judicial organization. The criminal talks about how the crime happened and about his reasons and motivations to commit it. And victim talks about the loss derived from crime, his requirements, and desires. In such a situation, a neutral third party without benefits in this course (mediator) guides and manages the conversation. Code of criminal procedure act 82 , has predicted mediation in crime deterrent of grade $6,7,8$ and its execution is subject to parties agreement. Based on mentioned act, it has considered 2 months or 4 months (for any required extension to get plaintiff forgiveness and loss recovery resulted from crime), and 3 months or 6 months (for mediation extension) to settle complaints by referring to mediation and claim resolution council. The long process of this prediction contradicts clearly with act 3 of the same law that emphasizes on the process to be as short as possible and to prevent criminal procedure from disorder or prolongation. In spite of that, even if a clear definition of mediation and its principles was presented, or even if the steps and the duration of mediation process was clarified, there still negative histories of getting illegal fund against mandatory file reference without state permissions. This procedure makes us worried because in act 82 there is a prediction about reference to claim resolution council with little difference that reference duration was considered 2 month in act 12 deputy resolution council which can be increased to 6 months. In case of using mentioned duration in act above, it is possible to increase it to 10 months. In addition to these generalizations and other ambiguities existing in act above, it can let jobbers to abuse this ten month duration in act 82 . This briefing satisfaction of the complainant doesn't suffice to mitigate our concerns because similar to these apparent limitations were noticed in act 12 and 8 in deputy resolution council texts but in terms of execution they didn't concern any of legal limitations. With all ambiguities and concerns, in inclusion of mediation in new codes of criminal procedure, there is an orientation towards 
restorative justice and its principles. This research's aim is to survey penal mediation role in settling claims among peasants in Guilan province. After investigating research literature we will analyze the statistical data considering what was done in questionnaire through interview with people in some villages in Guilan province. After that, we investigated penal mediation role in this province.

\subsection{Restorative Justice}

In simplest definition, we can consider restorative justice as a process by which all people involved in criminal event (both victim and victim) participate in looking for solution about criminal action results. However, giving comprehensive definition of restorative justice is not simple; since restorative justice has an inflexible nature and includes different programs and thoughts. All the definitions share points in noticing the role of the three fundamental pillars in the triangle of the restorative justice (victim, victim, and society) (Umbreit, 2010) in confronting with the crime, and the effects of its results rely on the needs and capabilities of the victim, victim, and society. Tony Marshal considers justice to be a process through which parties having a role in a particular crime come together to decide on the manner of behaving the consequences of the committed crime and its obligations for the future. Or in other words, restorative justice is an approach based on claiming the crime, which is involving the beneficiary parties and society in an active relationship with the legal institutions (Najafi Abrand Abadi, 2003: 22).

This manner, in Marshal's definition, the voluntarily nature of participation in the process of common negotiation and decision making can facilitate the negotiation by the mediation of authorities or a neutral person who are considered as the facilitators of the process of the negotiation. Finding a comprehensive answer for the crime and its effects and also analyzing the reasons for committing the crime and aiding the criminal in fulfilling his commitments towards the victim and local community are of the main characteristics of restorative justice (Jalali, 2015).

Umbreit (2010) defines restorative justice this way: restorative justice is a type of justice which tries to create a balance between the benefits of the victim and society with the need to social- reacceptance of the criminal and tries to make victim situation practically improved as much as possible. To this end, all the people who are effective to some extent in criminal incidence actively participate to create such a balance (Umbreit, 2010).

\subsection{The Principles of the Restorative Justice in Relation to the Criminal and the Victim}

In current justice systems it is possible that the victim in addition to not achieving the real expectations suffer more from the complexities or many attorneys. Therefore, this principle is a revolt against the induced damages to the criminal justice organization insensitive to the real sensitivities of the criminal justice. There is no obligation in the participation of the parties of the crime in restorative justice plan. Therefore, for those victims and criminals who are not willing to participate in such process, different but logical methods must be adopted for compensating damages meeting the restorative requirements (Gholami, 2014).

The restorative justice prefers reaction against the criminal in the initial levels of crime and recommends mediation in all levels of pre - crime, on crime and in the process of judgments. This is parallel with the maximum active cooperation of the criminal and the minimum violence against him and voluntarily participation of the claiming parties. This principle seeks to make the reaction against the criminal a moral reaction away from harshness and confrontation combined with respect towards the parties of the crime within the process of restorative justice (Abbasi, 2003). According to the first principle of the restorative justice, initially crime is violence towards humanly relationships among people and then violence towards the law governed by the government. The acceptance of this principle does not mean to neglect the importance of the law. Rather, the law is an important means of setting the people relationships with the government and towards themselves. However, it should be noted that the law has been passed on to prevent from violating the relationships between the people. In traditional criminal justice, emphasizing on the violence of the law and focusing on the means of violent reaction through execution actually violating the relationships between individuals and violating the rights of the victim are neglected. In this system, the criminal is sentenced and executed because of committing the crime. However, it is possible for him to never be informed of the critical consequences of his committed action towards the others (Morris\& Maxwell, 2003).

The second general principle of the restorative justice supervises the necessity of the participation of the victims including direct victims and indirect victims, local communities, and also the friends, family, and supporters of the victims and also criminals in performing justice. In other words, in traditional criminal law through referring to the criminal side the arrival of many indirect victims and those who are capable of participating in the performance of justice and compensating the loss of victims is prevented from and consequently it is possible that even the criminal is arrested or sentenced to imprisonment due to not paying the fine. While in restorative 
justice the possibility of the direct participation of victims and those who have a portion is provided. Hence, restorative justice is an opportunity for the participation of the community, school, church, mosque, family, any other religious- educational institutions, and the relevant pillars of society for resolving the problems caused by the crime and responding to the needs of the criminal and the victim (Morris\& Maxwell, 2003).

The third general principle of the restorative justice supervises the responding of the criminal towards the committed action and its consequences. The criminal must be confronted with the consequences of the committed action and its effects on the society, the victims, and even his own family and sympathize with the victims by directly experiencing their distasteful conditions and must be actively looking for the ways of compensating the incurred loss. Furthermore, he must introduce him/herself as a useful citizen through doing positive actions and undertaking a legal job and must also refrain from repeating the criminal act. On the other side, one of the objectives of performing restorative processes is to reach a settlement. While there is the possibility of taking revenge from the criminal following the commitment of the crime restorative justice is a method for reaching a settlement at whose consequence the criminal is considered neither oppressed nor anathemized. He must compensate the harmful effects of the crime with a feeling of responsibility and regretting so as to provide the possibility of repairing the relationships (Niaz Mand, 2012).

\subsection{The Concept of Justice Mediation and Its Various Kinds}

The word mediation is used in two meanings: one is the intervening between the two claiming parties in order to forgive the aggressor side by the victim in order to settle the claims. The other one is intercession near the judge in favor of the criminal in order to forgive his wrongdoing or discount in his punishment. In Arabic language the word mediation has been used in its second meaning. This word is derived from intercession meaning mate. It looks as if intercessor by putting his reputation near the ruler and being placed near the criminal has become his mate seeking to release him from the punishment he is being exposed to. What has been addressed in the Encyclopedia of Criminology under the entry of mediation has considered this a manner of deviation from the criminal process which might be used at every level from the moment the crime has taken place until before the criminal is being presented at the court (Najafi Abrand Abadi \& Hashem Beigi, 2011). However, it seems that regarding the objective of diversion it has expanded the concept and has considered the meaning as the presence at the court and at every level, from the moment the crime has taken place until the level of sentencing and its performance to be usable. In total, mediation is the manner of settling the claim without the mediation of the justice system. A process through which the necessity of the negotiation of participants with each other in order to reach an agreement regarding the proposed claim is emphasized and based on the free decision- making with participation of the parties claim is settled. Following the compilation of the dossier and the job of the criminal courts from one side, and the mass of criminal population from the other which have caused a deficiency in the efficiency of justice system regarding fighting against criminal and reforming the criminals also since two years ago criminal justice has gradually opened its gates under some conditions on popular participation one of whose manifestations is mediation (Najafi Abrand Abadi \& Hashem Beigi, 2011).

penal mediation is a triple process which is commenced regardless of the usual customs in criminal process on the basis of the previous agreement between the criminal and the victim with the presence of a third person called the intervener in order to settle the claims. In other words, this means that it is the victim and the criminal themselves whom, through several sessions either by direct negotiation or by indirect one, if required, letter writing, will reach a mutual agreement regarding their claims without the intervener inducing his opinion on them. In Note 82 the first matter is the matter of territory which includes the detention crimes of $6^{\text {th }}, 7^{\text {th }}$, and $8^{\text {th }}$ degree. Therefore, it can be said that it incorporates a lot of crimes. And in this regard the justice mediation is like the system of France; because in France the justice procedure has identified the crimes. In fact, it is something between the Common Law and France system (Najafi Abrand Abadi, 2004: 96).

\subsection{Defining the Criminal Mediation in Criminal Justice Custom}

Iranian law has expressed in Note 82 that" the legal authority can" and it is deduced that the court, in addition to the attorney can induce criminal mediation. And it expresses in Note 16 of the law of the establishment of the children and youth court that criminal mediation is also possible at performance level. Therefore, in this regard, it is similar to Common Law.

Note of Article 82: in Iran, the investigator cannot mediate but can ask the attorney to do so. Regarding the compatibility justice mediation must be through the agreement of both sides. This means that the rights of the criminal and the victim must be observed and the primary essence of mediation is mutual agreement. Therefore, it is impossible to refer to the mediation level without mutual satisfaction of the parties. However, the important point in the agreement is the criminal, meaning that the criminal appreciates that he has committed a crime and 
wants to eliminate its effects and criminal mediation is meaningless unless he accepts (Hussein Vand, 2015).

Mediation is a multi - dimensional entity considering the society, criminal and victim. It also desires establishing discipline in society, reforming criminal, and compensating the loss of victim. Sometimes compensating loss is possible by a simple apology. Here, the appreciation of the criminal means that he has accepted the committed action and tries to compensate. The acceptance and request are the initial condition of the Note and the criminal asks the attorney to grant him a two - month opportunity to gain the satisfaction of the complainant. Many say that this is not at all mediating. However, regarding the fact that they reach an agreement outside the legal system, it is close to societal criminal mediation. Because legal authority only determines an opportunity and does not conduct any other mediation and the parties go out within the determined time and talk to each other and they probably have a mediator outside and only its result is important to the attorney. Therefore, it is close to societal (Sabouhi, 2015).

In the second condition of Note 82 legal authority can also refer the subject by mutual agreement of the parties to a legal institution. Here, creativity is by the legal authority and societal- governmental. That is because legal authority and attorney allow for that and refer the issue to an institution. In fact, the second level is resolved through society but the permission of mediation is by legal authority. After issuing the command, the first mediator must talk to the criminal and victim separately to comprehend their desires. Then he holds a common session. If mediation is successful, based on law, if the subject has been forgivable, then persuasion is ceased and persuasion cease fixity is induced and the forgiveness of complaint is inserted in records of claim resolution council and the next reference of complaint is not needed (Najafi Abrand Abadi, 2004: 96).

\section{Research Method}

The present research has been conducted with the intention of analyzing mediation as a manifestation of criminal justice among rural people of Guilan province. The focus is on practical objective and the method is based on secondary analysis for gathering data using data from gathered questionnaires of 160 people of several different villages of Guilan province. Our observation unit is individual and data have been gathered on the basis of variables of the research using the questionnaire. Using SPSS software, we have extracted, interpreted, and assessed the results.

\section{Results}

\subsection{Descriptive Analysis}

Q1- Has anybody of the residents of the village ever committed a crime against you?

Table 1. Frequency distribution related to question 1

\begin{tabular}{ccc}
\hline Question 1 & Frequency & Frequency percentage \\
\hline Yes & 133 & 83.1 \\
No & 27 & 16.9 \\
Total & 160 & 100 \\
\hline
\end{tabular}

As you can see in table $1,83.1 \%$ of respondents against whom the residents of the village have committed a crime and $16.9 \%$ against whom no crime has been committed. Regarding the present statistics it can be said that in villages there are so many claims maybe the most important reason of which is property claim, racial- tribunal bigotries and particular customs of the rural people.

Q2- Have you ever referred to the court and the attorney as complaining?

Table 2. Frequency distribution related to question 2

\begin{tabular}{ccc}
\hline Question 2 & Frequency & Frequency percentage \\
\hline Yes & 70 & 43.8 \\
No & 90 & 56.3 \\
Total & 160 & 100 \\
\hline
\end{tabular}


As you can see in table $2,43.8 \%$ of the respondents have referred to attorney as complaining and $56.3 \%$ have never been referred to attorney as complaining. Statistics indicate that most respondents believe that they have not referred to the attorney and believe more in mediation method and settlement of claims through trustworthy and elderly people of the village.

Q3- In case of any claim among the residents of the village are the elderly of village willing to intermediate among the parties?

Table 3. Frequency distribution related to question 3

\begin{tabular}{ccc}
\hline Question 3 & Frequency & Frequency percentage \\
\hline Very low & 0 & 0.0 \\
Low & 0 & 0.0 \\
Medium & 3 & 1.9 \\
Much & 40 & 25 \\
Very much & 117 & 73.1 \\
Total & 160 & 100 \\
\hline
\end{tabular}

As you can see in table 3, from the respondents' perspective, $1.9 \%$ in medium level, $25 \%$ much and $73.1 \%$ in very much level in case of any claim among the residents of the village, the elderly of the village are willing to intermediate between the parties. The results of this question indicate that the elderly of the villages in Guilan province in case of any claim have the feeling of being responsible and play their role through intermediate and they are not indifferent towards the claims of their fellow citizen.

Q4- Does the settlement of claims through the criminal intermediate (session of the elderly) unlike investigation by legal authorities lead to claim settlement and compensation of the loss?

Table 4. Frequency distribution related to question 4

\begin{tabular}{ccc}
\hline Question 4 & Frequency & Frequency percentage \\
\hline Very low & 0 & 0.0 \\
Low & 5 & 3.1 \\
Medium & 96 & 60 \\
Much & 30 & 18.8 \\
Very much & 29 & 18.1 \\
Total & 160 & 100 \\
\hline
\end{tabular}

As you can see in table $4,3.1 \%$ of the respondents believed that claim settlement by the elderly unlike investigation by legal authorities is low, $60 \%$ expressed that it is medium, $18.8 \%$ expressed it to be much and $18.1 \%$ expressed that it leads very much to claim settlement. The statistics indicate that the majority of the respondents believe that in case there is a claim in the village and this claim is investigated in legal authority and eventually lead to claim settlement, the parties will still have claims and there is still annoyance between them and regarding the fact that they live in the same village, this might cause another claim and may even become more intense. Whereas if the same claim would be resolved through the intermediate of the elderly in the village surely the annoyance would be resolved and the parties involved in the claim would reach an agreement and familial relationships would exist between those families. Therefore, it should be noted by legal authorities that the claim between the parties involved in the conflict will not be resolved merely by making a sentence. Rather, some approaches and strategies must be taken into account including referring them to the claim resolution council or the command of performing the sentence by this council in the village in the order of definite resolution and definite reform of interpersonal.

Q5- Will the claim caused by intermediary be permanent and stable? 
Table 5. Frequency distribution related to question 5

\begin{tabular}{ccc}
\hline Question 5 & Frequency & Frequency percentage \\
\hline Very low & 0 & 0.0 \\
Low & 0 & 0.0 \\
Medium & 21 & 13 \\
Much & 102 & 63 \\
Very much & 39 & 24.1 \\
Total & 162 & 100 \\
\hline
\end{tabular}

As you can see in table $5,13 \%$ of the respondents expressed that the settlement caused by intermediary is stable in medium degree, $63 \%$ of the respondents expressed that to be much and $24.1 \%$ expressed that to be very much permanent and stable. The results indicate that the settlement caused by intermediary will be permanent and certain and the same result had also gained in previous questions because intermediary is taken place by the elderly of the village and they are a part of the people of the same village themselves. And to some extent local supervision takes place and people observe the trespasser one so as not to make a mistake again.

\section{Discussion}

Criminal intermediary is a humanity method in confronting the humanity claims, which, beside the authoritative criminal justice system, by maintaining its dependency and also by observing a limitation of independency acts as a complementary mechanism and in most cases tackles the conflicts caused by criminal issues as an alternative. The fundamental objective of criminal intermediary is to balance the benefits and perspectives of the main pillars of criminal justice, namely the victim and the criminal as much as possible.

The results of analyzing statistical data illustrates that in villages of Guilan province, the claims and crimes are so much, maybe the majority of whose reasons is particular customs of the residents of the village, tribunal bigotries, and possessing claims. the majority of respondents believe they have never referred to the attorney and trust more instead on intermediary through the elderly of the village. The results illustrate that the village residents of the Guilan province are not so much satisfied with the manner of investigation and the induced sentence by legal authorities which can be an indicative of the more effectiveness of criminal intermediary through the elderly of the village than referring to legal authorities particularly taking into account the fact that in the villages of Guilan province, the residents of the village respect the elderly. The method of criminal intermediary can be very effective and successful in reducing the referring of the rural people to legal authorities and also in preventing form crimes.

The settlement caused by intermediary will be permanent and certain and the same result had also gained in questions because intermediary is taken place by the elderly of the village and they are a part of the people of the same village themselves. And to some extent, local supervision takes place and people observe the trespasser one so as not to make a mistake again.

The gained statistics illustrate that the majority of the rural people know the elderlies of the village and respect them in which case the familiarity can improve their trust and obedience of the residents from the warns and recommendations of the elderly and can lead to settling their claims. Furthermore, the results illustrate that much relative relationships take place within the villages of Guilan province and the majority of marriages is familial and this causes a firmness of relative relationships and the integration of the rural people. And consequently, the criminal intermediary method can be very effective in settling the claims.

The majority of the respondents in the villages of Guilan province are wholly familiar with arbitration (e.g. practiced by the headman of a village). The results illustrate that the rural people of Guilan province welcome more the intermediary approach in settlement of their claims than referring to legal authorities. Therefore, criminal intermediary must be made a culture as much as possible and must even be educated. Furthermore, in case of any claims the elderly will intermediate and they are not indifferent towards the claims of the rural people living in their village.

The results illustrate that the rural people of Guilan province trust and believe more in their elderly people for settlement of their claims than other legal authorities. So, we can say that penal mediation is an effective method in settlement of claims of the rural people of Gialn province and for them respecting the elderly is a favorable thing and is a part of their ethics in which case this good manner can be very effective in settlement of their 
claims. And we can think of criminal intermediacy in rural people of Guilan province as one of the arms of legal authorities of the province in reducing criminal files and preventing from people travelling back and forth in legal authorities.

\section{References}

Abbasi, M. (2010). New horizons of restorative justice in criminal intermediary (1st ed.). Tehran: Daneshvar Press.

Gholami, H. (2014). Restorative justice (2nd ed.). Tehran: Samt Press.

Hussein Vand, M. (2015). Intermediary in the shadow of restorative justice teachings with an inquiry in the law of criminal justice custom passed in 2013 (1st ed.) Tehran: Majd Press.

Jalali, N. (2015). Historical grounds of restorative justice in Criminal Law of Iran (2nd ed.). Tehran: Tan'im Press.

Light, M. (2014). Restorative justice (from theory to practice) in addition to the developing file of restorative justice in Europe (1st ed.). Tehran: Jungle Press.

Morris, A., \& Maxwell, G. (Eds.). (2001). Restorative justice for juveniles: Conferencing, mediation and circles. Bloomsbury Publishing.

Najafi Abrand Abadi, A. H. (2003). From classical criminal justice to restorative justice. Journal of Razavi University of Islamic Sciences, 2(9/10), 25-38.

Najafi Abrand Abadi, A. H., \& Hashem Beigi, H. (2011). Encyclopedia of Criminology (1st ed.). Tehran: Ganje Danesh Press.

Najafi Abrand Abadi, A. H., Hossein, A., Shadmanfar, M. R., \& Tavajjohi, A. (2008). Restorative Justice. Human Science Instructor, 58, 193-222.

Niaz Mand, N. (2012). Victim children and pathology of restorative justice teachings (law of Iran and Britain) (1st ed.). Tehran: Ganje Danesh Press.

Sabouhi, R. (2015). Restorative justice in criminal system subject of Iran (1st ed.). Tehran: Majd press.

Umbreit, M. (2010). Restorative justice dialogue: An essential guide for research and practice. Springer Publishing Company. https://doi.org/10.1177/0734016811402028

\section{Copyrights}

Copyright for this article is retained by the author(s), with first publication rights granted to the journal.

This is an open-access article distributed under the terms and conditions of the Creative Commons Attribution license (http://creativecommons.org/licenses/by/4.0/). 